\title{
Perbedaan Luaran Maternal dan Perinatal pada Ibu Bersalin Usia Reproduksi Sehat dan Usia Berisiko
}

\author{
Seri Wahyuni ${ }^{1}$, Riyanti ${ }^{2}$ \\ ${ }^{1,2}$ Jurusan Kebidanan, Politeknik Kesehatan Kemenkes Palangka Raya, Indonesia \\ Email: adilahidayat@gmail.com
}

\begin{abstract}
Differences in Maternal and Perinatal Outcomes of Maternal Mothers of Healthy Reproductive Age and Risk. The old age mother has a risk to get a complication in pregnancy and parturition much higher than reproductive age mother. According to Yensi study (2015), that of the 226 women giving birth over the age of 35 years, as many as 125 people $(55.3 \%)$ had a history of abnormal pregnancy. In addition, most of the type of labor is by Sectio Caesarea (SC) a total of 119 $(51.7 \%)$ and suffered complications as much as $44.7 \%$. This study was to identify differences in maternal and perinatal outcomes between healthy reproductive age and risky age maternal in Cempaka Room, Doctor Doris Sylvanus Regional Public Hospital, Palangkaraya. The study design was case-control, data retrieved by conducting interviews at birth mothers in the Cempaka room dr. Doris Sylvanus Palangkaraya. The research sample consisted of 30 samples of mothers of reproductive age (20-35 years) and 30 samples of old-risk maternal age ( $>35$ years). The Data were taken from September to November 2016. Data were analyzed by Chi-Square, Odds ratio, and logistic regression analysis. The results showed that birth weight babies in reproductive age maternal different from risky age maternal $(\mathrm{OR}=7,95 \% \mathrm{CI}=1.4$ to 35.5$)$. This means that the risky age maternal has seven times greater to give birth a baby with body weight $<2500 \mathrm{~g}$ or $>4000 \mathrm{~g}$. While maternal and perinatal outcomes on the kind of labor, bleeding, gestation, and asphyxia no difference. The difference of perinatal outcomes in the maternal reproductive age between healthy reproductive age and risky age maternal was of infant birth weight. It was recommended that pregnant women and maternity in the age range of 20-35 years.
\end{abstract}

Keywords: Maternal out come, Perinatal outcome, Maternal age

\begin{abstract}
Abstrak: Perbedaan Luaran Maternal dan Perinatal pada Ibu Bersalin Usia Reproduksi Sehat dan Usia Berisiko. Latar Belakang: Ibu bersalin usia berisiko memiliki faktor risiko untuk mendapatkan komplikasi kehamilan dan persalinan yang lebih banyak dari ibu usia reproduksi sehat. Menurut Penelitian yensi (2015) bahwa dari 226 ibu bersalin diatas usia 35 tahun,sebanyak 125 orang $(55,3 \%)$ memiliki riwayat kehamilan yang tidak normal. Selain itu dari jenis persalinan terbanyak yaitu dengan Sectio Caesarea (SC) sebanyak 119 (51,7\%), dan mengalami komplikasi sebanyak $44,7 \%$. Tujuan penelitian ini adalah mengetahui perbedaan luaran maternal perinatal pada ibu bersalin usia reproduksi sehat dan usia berisiko di Ruang Cempaka RSUD dr. Doris Sylvanus Palangka Raya. Desain penelitian ini adalah case control, data diambil dengan melakukan wawancara pada ibu bersalin di ruang cempaka RSUD dr. Doris Sylvanus Palangka Raya. Sampel penelitian yang terdiri dari 30 sampel ibu usia reproduksi (20-35 tahun) dan 30 sampel ibu bersalin usia berisiko tua (>35 tahun) dan. Data diambil periode September-November 2016. Data dianalisis dengan uji Chi Square, rasio Odds, dan analisis uji regresi logistik. Hasil penelitian menunjukkan bahwa berat badan lahir bayi pada ibu usia reproduksi sehat berbeda dengan ibu bersalin usia berisiko $p=0,01(\mathrm{OR}=7$, CI 95\%=1,4-35,5). Hal ini berarti bahwa Ibu bersalin usia berisiko memiliki peluang 7 kali lebih besar melahirkan bayi dengan berat badan $<2500$ gr atau $>4000$ gram. Sedangkan luaran maternal dan perinatal pada jenis persalinan, perdarahan, usia kehamilan dan asfiksia tidak ada perbedaan. Ada perbedaan luaran perinatal pada Ibu bersalin usia reproduksi sehat dan usia risiko yaitu pada berat badan lahir bayi. Sebaiknya ibu hamil dan bersalin pada rentang usia 20-35 tahun.
\end{abstract}

Kata kunci: Luaran maternal, Luaran perinatal, Usia ibu bersalin

Persalinan merupakan proses alamiah yang harus dilewati oleh setiap wanita hamil. Petugas kesehatan memiliki peran dalam memantau persalinan untuk mendeteksi adanya komplikasi, disamping memberikan bantuan dan dukungan kepada ibu bersalin. Tidak sedikit ibu bersalin dan bayi mengalami trauma karena penanganan yang kurang baik (Saifuddin, 2009). 
Risiko adalah suatu ukuran statistik dari peluang atau kemungkinan untuk terjadinya suatu keadaan gawat-darurat yang tidak diinginkan pada masa mendatang, yaitu kemungkinan terjadi komplikasi obstetrik pada saat persalinan yang dapat menyebabkan kematian, kesakitan, kecacatan, atau ketidakpuasan pada ibu atau bayi (Rochjati, 2003).

Usia risiko tinggi adalah di bawah 20 tahun dan di atas 35 tahun. Penyebab terbanyak karena pendarahan dan eklamsia atau kejang akibat tekanan darah tinggi. Menurut beberapa penelitian, usia produktif yang optimal untuk reproduksi sehat adalah antara 20-35 tahun. Risiko akan meningkat pada usia di bawah 20 tahun maupun di atas 35 tahun. Wanita hamil pada usia muda akan memiliki beberapa risiko diantaranya adalah keguguran, persalinan prematur, BBLR, kelainan bawaan, mudah terjadi infeksi, anemia pada kehamilan, keracunan kehamilan (gestosis), dan kematian (BKKBN, 2006). Demikian juga wanita yang menjalani kehamilan pada usia lebih dari 35 tahun memiliki kemungkinan mengalami kelahiran risiko tinggi seperti melahirkan bayi dengan kelainan mental atau down syndrome (Detiana, 2010).

Seiring dengan berkembangnya zaman, fenomena transisi kependudukan menyebabkan perubahan pada struktur kependudukan terutama struktur penduduk menurut umur. Bila sebelumnya penduduk yang terbesar adalah anak-anak, maka dalam masa transisi ini proporsi penduduk usia remaja semakin besar. Menikah di usia muda kian menjadi tren di masyarakat Indonesia saat ini. Hal ini akan berkaitan juga dengan meningkatnya angka kehamilan di usia muda. Sebuah survei tahun 1995 mendapatkan 21,5\% perempuan Indonesia menikah pada usia 17 tahun (Dharmayanti, 2009).

Proses melahirkan pada perempuan berusia di atas 35 tahun ke atas berisiko menyebabkan terjadinya pendarahan. Biasanya, kondisi ini rentan terjadi pada ibu-ibu yang melahirkan anak pertama atau bagi ibu yang melahirkan anak ketiga atau keempat. Hamil dan melahirkan di atas usia 35 tahun selalu dianggap berisiko tinggi. Baik untuk janin maupun sang ibu yang mengandung (Kurniati, 2009).

Dampak kejadian persalinan pada ibu yang berusia >35 tahun yaitu risiko bagi ibu diantaranya adalah tekanan darah tinggi dan diabetes, pendarahan yang dapat membahayakan ibu dan bayinya, bayi dilahirkan secara Caesar, terjadi kehamilan di luar rahim. Sedangkan risiko pada bayi adalah cacat bawaan bisa berupa kelainan kromosom pada anak, keguguran dikarenakan penurunan kemampuan rahim untuk menerima janin, risiko meninggalnya bayi yang dilahirkan, persalinan dengan bayi prematur (berat lahir rendah) (Saifuddin, 2009).

Risiko tinggi komplikasi adalah keadaan penyimpangan dari normal yang secara langsung menyebabkan kesakitan dan kematian ibu maupun bayi. Persalinan dengan risiko tinggi memerlukan perhatian serius, karena pertolongan akan menentukan tinggi rendahnya kematian ibu dan neonatus (perinatal). Untuk menurunkan AKI secara bermakna maka deteksi dini dan penanganan ibu hamil berisiko atau komplikasi kebidanan perlu lebih ditingkatkan baik fasilitas pelayanan KIA maupun di masyarakat (Niken, Meilani dkk, 2009)

Berdasarkan laporan register Ruang Cempaka di RSUD dr. Doris Sylvanus Palangka Raya pada 2 tahun terakhir diperoleh jumlah persalinan pada tahun 2012 yang umur $>35$ tahun ada 122 kasus atau 10,44\% dari 1168 persalinan, sedangkan pada tahun 2013 ada sebanyak 132 kasus atau 10,78\% dari 1224 persalinan. Menurut Penelitian yensi tahun 2015 bahwa dari 226 ibu bersalin di atas usia 35 tahun,sebanyak 125 orang $(55,3 \%)$ memiliki riwayat kehamilan yang tidak normal. Selain itu dari jenis persalinan terbanyak yaitu dengan Sectio Caesarea (SC) sebanyak 119 $(51,7 \%)$, dan mengalami komplikasi sebanyak $44,7 \%$. Pada data tersebut menunjukkan masih tingginya ibu yang melahirkan pada usia berisiko yaitu di atas 35 tahun. Tren ibu yang melahirkan di atas 35 semakin meningkat. Seiring bertambahnya umur bagi wanita, fungsi organ reproduksi seperti indung telur dan rahim makin kurang optimal tidak seperti saat usia 20 tahunan, fungsi hormonalnya mulai berkurang, fisik untuk mengejan pun sudah dirasa tak sekuat dahulu, namun segi psikologis dan finansial lebih mapan dari usia di bawah 40 tahun. Komplikasi seperti preeklampsia (hipertensi saat kehamilan), hamil di luar rahim, keguguran, bayi terkena down syndrome, keracunan kehamilan, pendarahan hebat, anemia, diabetes sampai kesulitan melahirkan sangat menghantui ibu-ibu yang akan melahirkan di usia 40-an. Gangguan persalinan yang paling umum adalah plasenta previa yakni plasenta menutupi jalan lahir (Prawiroharjo, 2009).

Berdasarkan data di atas maka peneliti tertarik untuk melakukan penelitian tentang perbedaan luaran maternal dan perinatal pada ibu bersalin usia reproduksi sehat dan berisiko di Ruang Cempaka RSUD dr. Doris Sylavanus Palangka Raya.

Penelitian ini bertujuan untuk mengetahui perbedaan luaran maternal perinatal pada ibu bersalin usia reproduksi sehat dan usia berisiko di 
Ruang Cempaka RSUD dr. Doris Sylvanus Palangka Raya.

\section{METODE}

Penelitian ini adalah penelitian observasional analitik dengan rancangan case control dengan pendekatan retrospektif. Penelitian ini dimulai dengan mengidentifikasi pasien dengan efek (kasus) dan pasien tanpa efek (kontrol). Populasi pada penelitian ini adalah seluruh ibu yang melahirkan di VK Bersalin Ruang Cempaka RSUD dr. Doris Sylvanus Palangka Raya pada bulan September Juli s.d November tahun 2016 sebanyak 60 orang. Sampel pada penelitian ini dibagi menjadi dua kelompok yaitu 30 pada kelompok kasus dan 30 kelompok kontrol.

Pemilihan sampel dipilih dengan menggunakan consecutive sampling yaitu setiap pasien yang memenuhi kriteria inklusi dan eksklusi dijadikan sampel kelompok kasus dan kelompok kontrol penelitian. Kelompok kasus adalah ibu bersalin yang memenuhi kriteria inklusi yaitu ibu bersalin, bersedia menjadi responden, berusia $<20$ tahun, dan $>35$ tahun di VK Bersalin Ruang Cempaka RSUD dr. Doris Sylvanus Palangka Raya. Sedangkan kelompok kontrol dengan kriteria ibu bersalin, bersedia menjadi responden, usia 20-35 tahun.

Pengumpulan data dilakukan dengan cara melakukan wawancara langsung pada responden/ibu yang berusia $<20$ tahun, 20-35 tahun dan $>35$ tahun yang mendapat pelayanan di VK Bersalin Ruang Cempaka RSUD dr. Doris Sylvanus Palangka Raya.

Data dianalisis dengan program komputer. Analisis bivariat digunakan dengan chi square $\left(\mathrm{X}^{2}\right)$ bila tidak memenuhi syarat dengan menggunakan uji fisher exact test.

\section{HASIL}

Tabel 1. Ukuran Pemusatan dan Ukuran Penyebaran Ibu Bersalin Usia Reproduksi Sehat dan Usia Berisiko

\begin{tabular}{|c|c|c|c|}
\hline & \multirow{2}{*}{$\begin{array}{c}\text { Usia } \\
\text { reproduksi } \\
\text { sehat }\end{array}$} & \multicolumn{2}{|c|}{ Usia berisiko } \\
\hline & & $\begin{array}{c}<20 \\
\text { tahun }\end{array}$ & $\begin{array}{c}>35 \\
\text { tahun }\end{array}$ \\
\hline Mean & 27 & 17,8 & 39,7 \\
\hline Median & 26 & 18 & 40 \\
\hline Modus & 24 & 19 & 36 \\
\hline Minimum & 21 & 16 & 36 \\
\hline Maksimum & 35 & 19 & 44 \\
\hline Standar & 4,12 & 1,25 & 1.33 \\
\hline Deviasi & & & \\
\hline
\end{tabular}

Tabel 2. Distribusi Frekuensi Ibu Bersalin Usia Reproduksi Sehat dan Usia Berisiko

\begin{tabular}{|c|c|c|c|c|}
\hline \multirow[t]{2}{*}{$\begin{array}{c}\text { Usia } \\
\text { (tahun) }\end{array}$} & \multicolumn{2}{|c|}{$\begin{array}{l}\text { Kelompok ibu } \\
\text { bersalin usia } \\
\text { reproduksi } \\
\text { sehat }\end{array}$} & \multicolumn{2}{|c|}{$\begin{array}{l}\text { Kelompok ibu } \\
\text { bersalin usia } \\
\text { berisiko }\end{array}$} \\
\hline & Jlh & $\%$ & Jlh & $\%$ \\
\hline 16 & - & - & 2 & 6,7 \\
\hline 17 & - & - & 3 & 10 \\
\hline 19 & - & - & 5 & 16,7 \\
\hline 21 & 2 & 3,3 & - & - \\
\hline 22 & 3 & 5 & - & - \\
\hline 23 & 1 & 1,7 & - & - \\
\hline 24 & 4 & 6,7 & - & - \\
\hline 25 & 1 & 1,7 & - & - \\
\hline 26 & 4 & 6,7 & - & - \\
\hline 27 & 1 & 1,7 & - & - \\
\hline 28 & 3 & 5 & - & - \\
\hline 29 & 1 & 1,7 & - & - \\
\hline 30 & 2 & 3,3 & - & - \\
\hline 31 & 3 & 5 & - & - \\
\hline 32 & 2 & 3,3 & - & - \\
\hline 33 & 1 & 1,7 & - & - \\
\hline 35 & 2 & 3,3 & - & - \\
\hline 36 & - & - & 5 & 16,7 \\
\hline 37 & - & - & 2 & 6,7 \\
\hline 38 & - & - & 2 & 6,7 \\
\hline 40 & - & - & 2 & 6,7 \\
\hline 41 & - & - & 2 & 6,7 \\
\hline 42 & - & - & 1 & 3,3 \\
\hline 43 & - & - & 4 & 13,3 \\
\hline 44 & - & - & 2 & 6,7 \\
\hline Jumlah & 30 & 100 & 30 & 100 \\
\hline
\end{tabular}

Berdasarkan hasil penelitian usia ibu bersalin usia reproduksi sehat rata rata berusia 27 tahun dengan usia paling muda berusia 21 tahun dan paling tua 35 tahun. Sedangkan pada ibu bersalin dengan usia berisiko $<20$ tahun rata-rata berusia 17,8 tahun dengan usia ibu bersalin paling muda 16 tahun dan usia $>35$ tahun rata rata berusia 39,7 tahun dengan usia bersalin paling tua 44 tahun. 
Tabel 3. Distribusi Frekuensi Jenis Persalinan, Frekuensi Perdarahan, Usia Kehamilan, Berat Badan Lahir Bayi, dan Status Asfiksia pada Ibu Bersalin Usia Reproduksi Sehat dan Usia Berisiko

\begin{tabular}{|c|c|c|c|c|c|c|}
\hline \multirow{3}{*}{ Variabel } & \multicolumn{4}{|c|}{ Kelompok } & \multirow{3}{*}{ Jlh } & \multirow{3}{*}{$\%$} \\
\hline & \multicolumn{2}{|c|}{$\begin{array}{c}\text { Ibu bersalin } \\
\text { usia } \\
\text { reproduksi } \\
\text { sehat } \\
\end{array}$} & \multicolumn{2}{|c|}{$\begin{array}{c}\text { Ibu } \\
\text { bersalin } \\
\text { usia } \\
\text { berisiko } \\
\end{array}$} & & \\
\hline & Jlh & $\%$ & Jlh & $\%$ & & \\
\hline \multicolumn{7}{|c|}{ Jenis Persalinan } \\
\hline Spontan & 12 & 63,2 & 7 & 36,8 & 19 & 31,7 \\
\hline $\mathrm{SC}$ & 18 & 43,9 & 23 & 56,1 & 41 & 68,3 \\
\hline \multicolumn{7}{|c|}{ Perdarahan } \\
\hline Tidak & 28 & 52,8 & 25 & 47,2 & 52 & 86,7 \\
\hline Ya & 2 & 28,6 & 5 & 71,4 & 7 & 13,3 \\
\hline \multicolumn{7}{|c|}{ Usia kehamilan } \\
\hline Preterm & 3 & 42,9 & 4 & 57,1 & 7 & 88,3 \\
\hline Aterm & 27 & 50,9 & 26 & 49,1 & 53 & 11,7 \\
\hline \multicolumn{7}{|c|}{ Berat badan lahir bayi } \\
\hline Normal & 28 & 58,3 & 20 & 41,7 & 48 & 80,0 \\
\hline Tidak & 2 & 16,7 & 10 & 83,3 & 12 & 20,0 \\
\hline \multicolumn{7}{|l|}{ Normal } \\
\hline \multicolumn{7}{|l|}{ Asfiksia } \\
\hline Tidak & 20 & 60,6 & 13 & 39,4 & 33 & 55,0 \\
\hline $\mathrm{Ya}$ & 10 & 37,0 & 17 & 63 & 27 & 45,0 \\
\hline Jumlah & 30 & 100 & 30 & 100 & 60 & 100,0 \\
\hline
\end{tabular}

Tabel 4. Perbedaan Luaran Maternal dan Perinatal pada Ibu Bersalin Usia Reproduksi Sehat dan Usia Berisiko

\begin{tabular}{cccccc}
\hline \multirow{2}{*}{ Variabel } & $\begin{array}{c}\text { Usia } \\
\text { Reproduksi } \\
\text { Sehat }\end{array}$ & $\begin{array}{c}\text { Usia } \\
\text { Berisiko }\end{array}$ & OR & $\begin{array}{c}\text { IK } \\
(\mathbf{9 5 \%})\end{array}$ & $p$ \\
\cline { 2 - 7 } & $\mathbf{n} \quad \%$ & n & $\%$ & & \\
\hline
\end{tabular}

\begin{tabular}{lrrrrrrr} 
& $\mathbf{n}$ & $\%$ & $\mathbf{n}$ & $\%$ & & & \\
\multicolumn{2}{l}{ Luaran Maternal } & & & & & & \\
\hline $\begin{array}{l}\text { Jenis Persalinan } \\
\text { - Spontan }\end{array}$ & & & & & & & \\
- SC & 12 & 63,2 & 7 & 36,8 & 2,2 & $0,7-6,7$ & $0,16^{\mathrm{a}}$ \\
$\begin{array}{l}\text { Perdarahan } \\
\text { - Tidak }\end{array}$ & 18 & 43,9 & 23 & 56,1 & & & \\
- Ya & 28 & 52,8 & 25 & 47,2 & 2,8 & $0,4-15,7$ & $0,42^{\mathrm{b}}$ \\
Usia & 2 & 28,6 & 5 & 71,4 & & & \\
Kehamilan & & & & & & & \\
- Preterm & 3 & 42,9 & 4 & 57,1 & 0,7 & $0,15-3,5$ & $1,00^{\mathrm{b}}$ \\
- Aterm & 27 & 50,9 & 26 & 49,1 & & & \\
\hline
\end{tabular}

Luaran Perinatal

Berat Badan Lahir

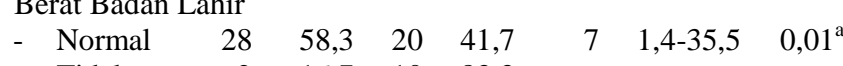

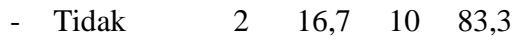

Normal

Asfiksia

$\begin{array}{llllllll}\text { - Tidak } & 20 & 60,6 & 13 & 39,4 & 2,6 & 1-7,5 & 0,07^{\mathrm{a}} \\ \text { - Ya } & 10 & 37,0 & 17 & 63,0 & & & \end{array}$

${ }^{\mathrm{a} U j i}$ Chi Square; ${ }^{\mathrm{b}} \mathrm{Uji}$ Fisher's exact; OR:Odd Ratio

\section{PEMBAHASAN}

Ibu bersalin usia berisiko lebih banyak melahirkan dengan SC $(56,1 \%)$ dibandingkan ibu bersalin usia reproduksi sehat $(43,9 \%)$. Hasil uji beda menunjukkan $p=0,16$ berarti tidak ada perbedaan bermakna pada jenis persalinan antara ibu bersalin usia reproduksi sehat dengan ibu usia berisiko. Hal ini menunjukkan bahwa usia berisiko maupun usia reproduksi sehat memiliki peluang yang sama untuk dilakukan tindakan sectio caesarea. Beberapa indikasi dilakukan operasi caesarea adalah bayi terlalu besar, letak sungsang, letak lintang, gawat janin, solutio plasenta dan plasenta previa. Menurut penelitian Salfariani (2012) tentang Faktor pemilihan persalinan sectio caesarea tanpa indikasi medis di RSU Bunda Thamrin Medan, persalinan sectio caesarea paling banyak di dapat ibu-ibu yang berpendidikan tinggi, karena pendidikan dapat mempengaruhi pengetahuan dalam pembentukan sikap mereka tentang tindakan sectio caesarea, pendidikan dapat membentuk keyakinan tertentu sehingga seseorang dapat mempunyai minat, kemampuan, pengalaman, ketrampilan dan tingkat perhatian.

Ibu bersalin usia berisiko lebih banyak mengalami perdarahan $(71,4 \%)$ dibandingkan ibu bersalin usia reproduksi sehat $(28,6 \%)$. Hasil uji beda menunjukkan $p=0,42$ berarti tidak ada perbedaan bermakna pada kejadian perdarahan antara ibu bersalin usia reproduksi sehat dengan ibu usia berisiko. Hasil ini menunjukkan bahwa risiko terjadi perdarahan postpartum pada ibu usia reproduksi sehat sama dengan ibu bersalin usia berisiko (OR=2,8, CI 95\%=0,4-15,7). Hal ini hampir sama dengan hasil yang didapatkan Demirci, et al (2016) bahwa ibu bersalin usia reproduksi sehat dan usia berisiko mempunya resiko mengalami perdarahan postpartum. Adapun faktor-faktor yang mempengaruhi kejadian perdarahan postpartum adalah partus lama, paritas, peregangan uterus yang berlebihan, oksitosin drip, anemia, dan persalinan dengan tindakan.

Ibu bersalin usia berisiko lebih banyak melahirkan berat badan lahir bayi tidak normal $(83,3 \%)$ dibandingkan ibu bersalin usia reproduksi sehat $(16,7 \%)$. Hasil uji beda menunjukkan $p=1,00$ berarti tidak ada perbedaan bermakna pada usia kehamilan antara ibu bersalin usia reproduksi sehat dengan ibu usia berisiko. Hasil ini menunjukkan bahwa usia kehamilan pada ibu usia reproduksi sehat sama dengan ibu bersalin usia berisiko (OR=0,7, CI $95 \%=0,154-1,00)$. Hal ini berbeda dengan hasil yang didapatkan Khalil, et al (2013) bahwa ibu bersalin usia berisiko 35-39 tahun memiliki resiko 1,28 kali dibandingkan usia ibu $<35$ tahun.

Ibu bersalin usia berisiko lebih banyak melahirkan berat badan lahir bayi tidak normal $(83,3 \%)$ dibandingkan ibu bersalin usia reproduksi sehat $(16,7 \%)$. Hasil uji beda 
menunjukkan $p=0,01$ berarti ada perbedaan bermakna berat badan bayi yang dilahirkan antara ibu bersalin usia reproduksi sehat dengan ibu usia berisiko. Hasil ini menunjukkan bahwa berat badan lahir bayi pada ibu usia reproduksi sehat berbeda dengan ibu bersalin usia berisiko $(\mathrm{OR}=7$, CI $95 \%=1,4-35,5)$. Hal ini sesuai dengan hasil yang didapatkan Yerebasmas, et al (2017) di Angkara Turkey bahwa ibu usia lanjut atau $\leq 35$ tahun akan mengalami berat badan lahir rendah 1,6 kali daripada usia reproduksi. Ibu usia lanjut atau $\leq 35$ tahun akan berpeluang 6,2 kali melahirkan bayi dengan berat badan bayi sangat rendah dibandingkan usia reproduksi sehat. Wanita hamil pada usia muda akan memiliki beberapa risiko, diantaranya adalah persalinan prematur, BBLR, kelainan bawaan, mudah terjadi infeksi, anemia pada kehamilan, keracunan kehamilan (gestosis) dan kematian. Seiring bertambahnya umur bagi wanita, fungsi organ reproduksi seperti indung telur dan rahim makin kurang optimal seperti saat usia 20 tahun. Selain itu komplikasi seperti preeklampsia serta kurang gizi pada ibu dapat memberikan pengaruh terhadap pertumbuhan janin di dalam rahim.

Ibu bersalin usia berisiko lebih banyak mengalami status asfiksia (63\%) dibandingkan ibu bersalin usia reproduksi sehat (37\%). Hasil uji beda menunjukkan $p=0,07$ berarti tidak ada perbedaan bermakna kejadian asfiksia antara ibu bersalin usia reproduksi sehat dengan ibu usia berisiko. Hasil ini menunjukkan bahwa kejadian asfiksia pada ibu usia reproduksi sehat berbeda dengan ibu bersalin usia berisiko $(\mathrm{OR}=2,6, \mathrm{CI}$ $95 \%=1-7,5)$. Hal ini sesuai dengan hasil yang didapatkan oleh Destaria (2011) bahwa ibu usia muda dan usia tua memiliki resiko mengalami komplikasi asfiksia. Asfiksia dapat disebabkan oleh beberapa faktor yaitu faktor ibu seperti: hipoksia ibu dan gangguan aliran darah uterus, preeklampsia dan eklampsia, perdarahan antepartum, partus lama, postmatur. Faktor plasenta merupakan pertukaran gas antara ibu dan janin dipengaruhi oleh luas dan kondisi plasenta, Asfiksia janin akan terjadi bila terdapat gangguan mendadak pada plasenta misalnya solusio

\section{DAFTAR PUSTAKA}

BKKBN. 2006. Tiap Tahun 15 Juta Remaja Melahirkan.

http://www.bkkbn.go.id/Webs/DetailRubri

k.php?MyID=517 (Diakses pada 28 Agustus 2010).

Demirci, O., Y1lmaz, E., Tosun, Ö., Kumru, P., Arınkan, A., Mahmutoğlu, D., ... \& Tarhan, plasenta dan perdarahan plasenta. Faktor fetus seperti kompresi umbilikus akan mengakibatkan terganggunya alirah darah dalam pembuluh darah umbilikus dan menghambat pertukaran gas antara ibu dan janin, lilitan tali pusat, tali pusat pendek, simpul tali pusat, prolaps tali pusat, bayi prematur, mekonium dalam ketuban dan depresi pusat pernapasan pada bayi baru lahir. Berdasarkan penelitian Wiradharma et al. (2016) yang dilakukan di RSUP Sanglah Denpasar menyebutkan bahwa kemungkinan komplikasi asfiksia disebabkan oleh ketuban pecah dini yang dapat mengakibatkan asfiksia, baik akibat kelahiran kurang bulan, sindrom gawat nafas, gangguan plasenta, maupun infeksi. Menurut penelitian Prianita (2010) yang dilakukan di RSUP Dr. Kariadi Semarang didapatkan bahwa kejadian asfiksia neonatorum cenderung lebih tinggi pada kelompok primigravida muda dan primigravida tua.

\section{SIMPULAN}

1. Tidak ada perbedaan luaran maternal pada Ibu bersalin usia reproduksi sehat dan usia berisiko antara lain jenis persalinan, usia kehamilan dan status perdarahan.

2. Luaran perinatal terdapat perbedaan antara luaran maternal dan perinatal pada ibu bersalin usia rerpoduksi sehat dan usia resiko pada berat badan lahir bayi dengan nilai $p=0,01$, untuk status asfiksia tidak terdapat perbedaan pada ibu bersalin usia reproduksi sehat dan usia berisiko.

\section{SARAN}

Bidan memberikan penyuluhan kepada remaja dan wanita untuk hamil dan bersalin pada usia reproduksi sehat antara 20 tahun s.d 35 tahun untuk menghindari terjadi berat badan $<2500$ gram dan $>4000$ gram.

N. 2016. Effect of young maternal age on obstetric and perinatal outcomes: results from the tertiary center in Turkey. Balkan medical journal, 33(3), 344.

Destaria, S., \& Pramono, B. A. 2011. Perbandingan luaran maternal dan perinatal kehamilan trimester ketiga antara 
usia muda dan usia reproduksi sehat. [Disertasi]. Semarang: Faculty of Medicine. Universitas Diponegoro.

Detiana. 2010. Hamil Aman dan Nyaman Diatas 30 Tahun. Yogyakarta: Media Pressindos.

Dharmayanti M. 2009. Overview Adolescent Health Problems and Services. http://www.idai.or.id/remaja/artikel.asp?q= 200994155149 (Diakses pada 12 Agustus 2010).

Khalil, A., Syngelaki, A., Maiz, N., Zinevich, Y., \& Nicolaides, K. H. 2013. Maternal age and adverse pregnancy outcome: a cohort study. Ultrasound in Obstetrics \& Gynecology, 42(6), 634-643.

Kurniati. 2009. Perempuan Melahirkan Diatas Usia $30 \quad$ Tahun. http://www.hariansumutpos.com (Diakses pada 22 Mei 2015).

Niken, Meilani dkk. 2009. Kebidanan Komunitas. Yogyakarta: Fitramaya.

Prawirohardjo, Sarwono. 2009. Buku Acuan Nasional Pelayanan Kesehatan Maternal dan Neonatal. Jakarta: PT Bina Pustaka Sarwono Prawirohardjo.
Prianita, A. W., \& Cahyanti, R. D. 2011. Pengaruh faktor usia ibu terhadap keluaran maternal dan perinatal pada persalinan primigravida di RS dr. Kariadi Semarang periode tahun 2010. [Disertasi]. Semarang: Faculty of Medicine. Universitas Diponegoro.

Rochjati, P. 2003. Skrinning Antenatal Pada Ibu Hamil. Surabaya: Pusat Safe Motherhood.

Saifuddin, AB. 2009. Panduan Praktis Pelayanan Kesehatan Maternal dan Neonatal. Jakarta: EGC.

Salfariani, Intan M., \& Nasution, S. S. 2012. Faktor Pemilihan Persalinan Sectio Caesarea Tanpa Indikasi Medis Di Rsu Bunda Thamrin Medan. Jurnal Keperawatan, 1(1), 7-12.

Wiradharma, W., Md, K. I., \& Wyn, D. A. I. 2016. Risiko asfiksia pada ketuban pecah dini di RSUP Sanglah. Sari Pediatri, 14(5), 316-9.

Yerebasmaz, N., AKDAĞ, D. C., Özdemirci, Ş., ERTÜRK, S., \& KAYIKÇIOĞLU, F. 2017. Does Advanced Maternal Age Increase the Risk of Adverse Perinatal Outcomes?. Acta Medica, 46(1). 